\title{
Characterization of depolymerized residues from extremely low acid hydrolysis (ELA) of sugarcane bagasse cellulose: Effects of degree of polymerization, crystallinity and crystallite size on thermal decomposition
}

\author{
Leandro Vinícius Alves Gurgel ${ }^{\mathrm{a}}$, Karen Marabezi ${ }^{\mathrm{a}}$, Luiz Antonio Ramos ${ }^{\mathrm{a}}$, \\ Antonio Aprigio da Silva Curvelo ${ }^{\mathrm{a}, \mathrm{b}, *}$

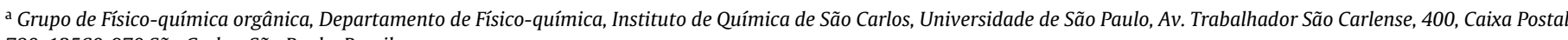 \\ 780, 13560-970 São Carlos, São Paulo, Brazil

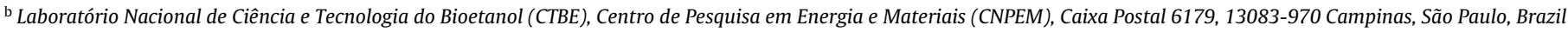

\section{A R T I C L E I N F O}

\section{Article history:}

Received 5 September 2011

Received in revised form 26 October 2011

Accepted 11 November 2011

Available online 14 December 2011

\section{Keywords:}

Sugarcane bagasse

Thermal decomposition

ELA

Microcrystalline cellulose

Acid hydrolysis

\begin{abstract}
A B S T R A C T
Sugarcane bagasse cellulose was subjected to the extremely low acid (ELA) hydrolysis in $0.07 \% \mathrm{H}_{2} \mathrm{SO}_{4}$ at 190,210 and $225^{\circ} \mathrm{C}$ for various times. The cellulose residues from this process were characterized by TGA, XRD, GPC, FTIR and SEM. A kinetic study of thermal decomposition of the residues was also carried out, using the ASTM and Kissinger methods. The thermal studies revealed that residues of cellulose hydrolyzed at 190,210 and $225^{\circ} \mathrm{C}$ for 80,40 and $8 \mathrm{~min}$ have initial decomposition temperature and activation energy for the main decomposition step similar to those of Avicel PH-101. XRD studies confirmed this finding by showing that these cellulose residues are similar to Avicel in crystallinity index and crystallite size in relation to the 110 and 200 planes. FTIR spectra revealed no significant changes in the cellulose chemical structure and analysis of SEM micrographs demonstrated that the particle size of the cellulose residues hydrolyzed at 190 and $210^{\circ} \mathrm{C}$ were similar to that of Avicel.
\end{abstract}

(c) 2011 Elsevier B.V. All rights reserved.

\section{Introduction}

Batch hydrolysis of cellulose to glucose by dilute acid hydrolysis results in yields limited to $60-65 \%$ of the potential glucose (Bouchard et al., 1989). Recently, The U.S. National Renewable Energy Laboratory (NREL) developed a dilute acid hydrolysis process for lignocellulose biomass called extremely low acid (ELA) hydrolysis. The ELA conditions employ low sulphuric acid concentration ( $0.07 \mathrm{wt} . \%)$ and high temperatures in order to improve the yield of glucose. According to Kim et al. (2001), there are distinct advantages of using extremely low acid (ELA) conditions for the hydrolysis of lignocellulosic biomass. One of them is that the corrosion characteristics of ELA conditions are very close to those of a neutral aqueous reaction, so that standard grade stainless steel equipment can be used instead of high nickel alloy, reducing equipment cost and maintenance. The advancement made in ELA has brought acid hydrolysis to a position where it can favorably

\footnotetext{
* Corresponding author at: Grupo de Físico-química orgânica, Departamento de Físico-química, Instituto de Química de São Carlos, Universidade de São Paulo, Av. Trabalhador São Carlense, 400, Caixa Postal 780, 13560-970 São Carlos, São Paulo, Brazil. Tel.: +55 163373 9938; fax: +55 1633739952 .

E-mail address: aprigio@iqsc.usp.br (A.A.S. Curvelo).
}

compete with enzymatic hydrolysis in overall process economics. Besides, the process using the ELA conditions could be regarded as an environmentally friendly process, as it has minimal environmental effects. Recent findings have proven that glucose yields around $62 \%$ are attainable when $\alpha$-cellulose is used as feedstock in a batch reactor.

In Brazil, first generation ethanol is mainly produced by fermentation of the sucrose in sugarcane juice. This is pressed from the cane by milling, leaving large amounts of bagasse. According to the last Brazilian crop survey performed by the National Company of Supply (CONAB, 2010), the estimated sugarcane harvest in the $2010 / 2011$ season is expected to reach 651.5 million tons, $7.8 \%$ greater than in 2009/2010, which will generate about 162.9 million tons of bagasse and 132.9 million tons of straw, given that one ton of sugarcane produces about $250 \mathrm{~kg}$ of bagasse and $204 \mathrm{~kg}$ of straw on a dry weight basis.

Sugarcane bagasse is mainly composed of cellulose, hemicelluloses and lignin. Cellulose, the subject of this study, is a linear homopolymer of D-glucopyranose units, which are linked by $\beta$ $(1 \rightarrow 4)$ glycosidic bonds. It contains amorphous and crystalline regions where the microfibrils are oriented randomly or in parallel bundles along the direction of cellulose fibrils, respectively. The amorphous region is more reactive than the crystalline, adding 
complexity to the thermal decomposition of cellulose (Shen \& Gu, 2009).

Numerous studies have been reported on the thermal degradation of cellulose, analyzed by thermogravimetry (TG) and differential thermal analysis (DTA). Mechanisms for thermal degradation of cellulose have been discussed by Broido and Nelson (1975), Bradbury et al. (1979), Wang et al. (2007) and Shen and Gu (2009). Calahorra et al. (1989) have also studied the effect of degree of polymerization and crystallinity index on thermal decomposition of cellulose. However, very little attention has been paid so far to the characteristics of the cellulose residues obtained from dilute acid hydrolysis. In this connection, Bouchard et al. (1989) were the first to investigate the thermal decomposition of cellulose residues as well as their structural changes, after dilute acid hydrolysis.

It is well known that the cellulose residues left after dilute acid hydrolysis have a lower degree of polymerization, higher crystallinity index, and large amounts of glucose decomposition products along their surface (Bouchard et al., 1989; Nelson \& Conrad, 1948; Sharples, 1957). Furthermore, these residues are resistant to further hydrolysis and $4 \% \mathrm{H}_{2} \mathrm{SO}_{4}$ at $121^{\circ} \mathrm{C}$ have been suggested as a favorable set of hydrolysis conditions to produce fermentable glucose from these residues (Xiang, 2002; Xiang et al., 2003a,b). However, these hydrolysis conditions are unfavorable compared to the ELA conditions, in relation to both acid concentration and hydrolysis time. Besides, according to Bouchard et al. (1989), the sugar potential of the unconverted cellulose residues decreases with the extent of depolymerization. Considering the physicochemical characteristics of cellulose residues a more economically profitable application needs to be also investigated.

However, the effects of the structural changes and the presence of decomposition products produced by dilute acid hydrolysis under the ELA conditions on the thermal decomposition of cellulose have not been investigated at present and, therefore, constitute an impediment to suggesting a new use for these residues. Thus, the main aim of this study was to investigate the effects of degree of polymerization, crystallinity index and crystallite size on the thermal decomposition of cellulose residues obtained from ELA hydrolysis conditions, by thermogravimetric analysis (TGA). A second aim of this study was to propose a commercial application for cellulose residues based on their physicochemical characteristics. For these purposes, sugarcane bagasse cellulose was prepared by extracting hemicelluloses prior to the soda-anthraquinone pulping process and subjecting the cellulose to ELA hydrolysis at high temperatures for various times. Gel permeation chromatography (GPC) and X-ray diffraction (XRD) were also used to investigate the changes in degree of polymerization, crystallinity index and crystallite size. Fourier transform infrared (FTIR) spectroscopy was used to investigate possible structural changes in the cellulose residues after dilute acid hydrolysis. Scanning electron microscopy (SEM) was employed in order to investigate the modification of fiber structure as well as the morphology and size of the particles.

\section{Experimental}

\subsection{Chemicals}

Sodium hydroxide and sulphuric acid (95-98\%) were purchased from Qhemis (Brazil). Anthraquinone (98\%) was provided by Lwarcel Cellulose (SP, Brazil). Avicel ${ }^{\circledR}$ PH-101 (microcrystalline cellulose, MCC) was purchased from FMC (Philadelphia, PA). Lithium chloride was purchased from Synth (Brazil). N,N'dimethylacetamide (HLPC grade) was purchased from Tedia (Brazil).

\subsection{Sugarcane bagasse cellulose preparation}

Sugarcane bagasse was provided by Ipiranga alcohol and sugar mill (São Carlos, SP, Brazil). Slices of raw bagasse were mechanically stirred in water at $70^{\circ} \mathrm{C}$ for $1 \mathrm{~h}$ to remove residual sugars from the milling process. The raw bagasse was then subjected to wet depithing, in order to separate the fiber and pith fractions, using a sieve system composed by two screens, of $16(1.19 \mathrm{~mm})$ and 60 $(0.250 \mathrm{~mm})$ mesh. Depithed bagasse was air dried to $10 \%$ moisture content. Hemicelluloses were extracted from the depithed bagasse in a $1000 \mathrm{~mL}$ Parr reactor. Sugarcane bagasse (65 g), containing $7.7 \%$ moisture, were loaded into the reactor with $715 \mathrm{~mL}$ of distilled water to give a solid-to-liquid ratio of $1: 12(\mathrm{w}: \mathrm{v})$. The reactor was heated to $160^{\circ} \mathrm{C}$ and maintained at this temperature for $1 \mathrm{~h}$, to hydrolyze the hemicelluloses. The reactor was then depressurized and the content transferred to a Buchner funnel and washed with an excess of water, to remove hydrolyzed hemicelluloses from the surface of the fibers. The moisture was again determined and the prehydrolyzed depithed bagasse was subjected to sodaanthraquinone pulping. For this process, $110.4 \mathrm{~g}$ of the material, containing 59\% moisture, were again loaded into the Parr reactor, with $9.34 \mathrm{~g}$ of $\mathrm{NaOH}$ ( 16 wt.\% of dry bagasse as $\mathrm{Na}_{2} \mathrm{O}$ ), $67.9 \mathrm{mg}$ of anthraquinone $(0.15 \%)$ and $523 \mathrm{~mL}$ of distilled water in order to give a solid-to-liquid ratio of $1: 13(\mathrm{w}: \mathrm{v})$. The reactor was heated to $160^{\circ} \mathrm{C}$ and kept at this temperature for $1 \mathrm{~h}$, after which the cellulose pulp was transferred to a Buchner funnel and washed with an excess of water, to remove soluble lignin from the pulp until the washings reached $\mathrm{pH} 6$. The moisture content was determined and the cellulose pulp was chilled to $-20^{\circ} \mathrm{C}$ and stored until used in acid hydrolysis experiments. The chemical composition of depithed bagasse, prehydrolyzed depithed bagasse and cellulose pulp was analyzed according to TAPPI standard methods for extractives (TAPPI, 1997), cellulose and hemicelluloses (TAPPI, 2000), Klason soluble and insoluble lignin (TAPPI, 2002), and ash (TAPPI, 1993).

\subsection{Batch acid hydrolysis experiments}

Samples of $0.6 \mathrm{~g}$ of the cellulose pulp obtained from prehydrolyzed depithed bagasse were loaded into $316 \mathrm{~L}$ stainless-steel reactors ( $25.0 \mathrm{~mm} \mathrm{OD} \times 15.7 \mathrm{~mm} \mathrm{ID} \times 83.2 \mathrm{~mm}$ length) with $12 \mathrm{~mL}$ $0.07 \% \mathrm{H}_{2} \mathrm{SO}_{4}(\mathrm{w} / \mathrm{v})$, to give a solid-to-liquid ratio of $1: 20(\mathrm{w}: \mathrm{v})$. The reactors were equipped with self-sealed o-ring closures made of PTFE fluoropolymer resistant to high temperatures $\left(>250^{\circ} \mathrm{C}\right)$. Samples were hydrolyzed at 190,210 , and $225^{\circ} \mathrm{C}$ for various times. The reactors were immersed in a glycerin bath heated to the desired reaction temperature. At the end of the experiments, the reactors were quenched in an ice bath to stop the reaction. The reactor contents were separated into liquid and solid by vacuum filtration in a sintered glass funnel. The residual cellulose was rinsed in water, dried at $60^{\circ} \mathrm{C}$ under reduced pressure $(100 \mathrm{mbar})$ and stored in a desiccator prior to analysis.

\subsection{Thermogravimetric analysis (TGA)}

Thermogravimetric analysis was carried out in a Shimadzu TA50 WSI attached to a TGA50 module. A sample of $4 \mathrm{mg}$ of cellulose residue was placed on a platinum pan. TGA experiments were performed under a nitrogen atmosphere at a flow rate of $50 \mathrm{~mL} / \mathrm{min}$. Samples were heated from 25 to $800^{\circ} \mathrm{C}$ at linear heating rates of $2.5,5,10$, and $20^{\circ} \mathrm{C} / \mathrm{min}$, as stipulated in the standard test method for decomposition kinetics by thermogravimetry (ASTM E 1641).

\subsection{X-ray diffraction $(X R D)$}

X-ray diffraction analysis was carried out in a Carl Zeiss Jena URD-6 diffractometer with monochromatic $\mathrm{Cu}-\mathrm{K} \alpha$ radiation 
$(\lambda=1.5406 \AA$ ), generated at a voltage of $40 \mathrm{kV}$ and a current of $20 \mathrm{~mA}$. The Bragg angle was varied from $3^{\circ}$ to $50^{\circ}$ at a scan rate of $2^{\circ} / \mathrm{min}$.

The peak profiles were resolved with Microcal Origin ${ }^{\mathrm{TM}} 8.5$ routines, Lorentz and Pearson VII functions being used for crystal peaks and a fifth-degree polynomial function for the background profile, following the method described by Kim et al. (2010). The crystallite size of the cellulose in the $\overline{110}, 110$ and 200 planes were calculated by the Scherrer equation (1), as follows:

$L_{h, k, l}=\frac{K \lambda}{H \cos \theta}$

where $K$ is the Scherrer constant $(0.89), \lambda(\mathrm{nm})$ is the X-ray wavelength, $H$ is the full-width at half-maximum (FWHM) in radians, and $\theta$ is the Bragg angle. The crystallinity index ( $\mathrm{CrI})$ was determined by the Segal method, from Eq. (2):

$\mathrm{CrI}=\left(\frac{I_{200}-I_{\mathrm{am}}}{I_{200}}\right) \times 100$

where $\mathrm{CrI}$ is the crystallinity index (\%), $I_{200}$ the maximum intensity of the ( 200 ) reflection, at $2 \theta$ of $22^{\circ}-23^{\circ}$, and $I_{\mathrm{am}}$ is the intensity of diffraction at $2 \theta$ of $18^{\circ}-19^{\circ}$ for cellulose I.

\subsection{Gel permeation chromatography (GPC)}

Gel permeation chromatography analysis was carried out with a Shimadzu system equipped with pump (LC-10AD), system controller (SCL-10A), and differential refraction index detector (RID-6A) and oven (CTO-10A). Lithium chloride (0.5 wt.\% LiCl) in $N, N^{\prime}$-dimethylacetamide (DMAc) was used as eluent $\left(60^{\circ} \mathrm{C}\right.$, $0.6 \mathrm{~mL} / \mathrm{min}$ ). The carbohydrates were separated in a series of columns, consisting of a pre-column of $10 \mu \mathrm{m}$ Plgel and two columns of $10 \mu \mathrm{m}$ mixed-B Plgel $(7.5 \mathrm{~mm}$ ID $\times 300 \mathrm{~mm})$ (Waters). The chromatogram was calibrated with Pullulan (Polymer Laboratories): 1,600,000, 380,000, 200,000, 107,000, 48,000, 23,700, $12,200,5,800,738$ and $342 \mathrm{~g} / \mathrm{mol}$ (cellobiose, Aldrich), $180 \mathrm{~g} / \mathrm{mol}$ (D-glucose, Aldrich), and $150 \mathrm{~g} / \mathrm{mol}$ (D-xylose, Aldrich). Both standards and cellulose samples were previously filtered on $1 \mu \mathrm{m}-25 \mathrm{~mm}$ acrodisc glass fiber disks (Waters), before injection of $100 \mu \mathrm{L}$ into GPC column.

Cellulose residues were dissolved in $\mathrm{LiCl} / \mathrm{DMAc}(0.5 \mathrm{wt} . \%)$ as follows. A sample ( $10 \mathrm{mg}$ ) was weighed and transferred to a roundbottom flask containing $0.25 \mathrm{~g}$ of $\mathrm{LiCl}$ and $5 \mathrm{~mL}$ of anhydrous DMAc, to give a concentration of $2 \mathrm{mg} / \mathrm{mL}$. A reflux condenser was attached to the reaction flask and the suspension was heated to $160^{\circ} \mathrm{C}$ under mild constant stirring for $90 \mathrm{~min}$. After this, the heating was turned off and the solution was stirred for a further $22.5 \mathrm{~h}$, giving a total reaction time of $24 \mathrm{~h}$.

\subsection{Fourier transform infrared spectroscopy (FTIR)}

The FTIR spectroscopy analysis was carried out on a Bomen MB spectrometer. Spectra were collected with 32 scans from 4000 to $400 \mathrm{~cm}^{-1}$ at a resolution of $2 \mathrm{~cm}^{-1}$. The sample was prepared by mixing $1 \mathrm{mg}$ of dried cellulose powder with $100 \mathrm{mg}$ of $\mathrm{KBr}$.

\subsection{Scanning electron microscopy (SEM)}

Dry powder samples were dispersed on a graphite ribbon fixed on an aluminum sample holder. The powder was sputter-coated with gold in a modular high-vacuum coating system and examined with a LEO-440 (Zeiss-Leica) scanning electron microscope, using a filament voltage of $20 \mathrm{kV}$.

\subsection{Theoretical approach}

The rate of a heterogeneous solid-state reaction can generally be described by Eq. (3):

$\frac{d \alpha}{d t}=k(T) f(\alpha)$

where $t$ is time, $k(T)$ is a constant that depends on the temperature $(T)$ and $f(\alpha)$ is a function that describes how the reaction rate constant changes with the extent of reaction or conversion, $\alpha . \alpha$ at $t$ is defined by Eq. (4):

$\alpha=\frac{w_{0}-w_{t}}{w_{0}-w_{\mathrm{ash}}}$

where $w_{0}(\mathrm{mg})$ is the initial sample weight, $w_{\text {ash }}(\mathrm{mg})$ is the final sample weight, and $w_{t}$ is the weight at time $t$.

Temperature dependence of the reaction rate constant can be described by the Arrhenius equation. Hence, the rate of a solid-state reaction can generally be expressed as:

$\frac{d \alpha}{d t}=A e^{\left(-E_{a} / R T\right)} f(\alpha)$

where $A$ is the pre-exponential factor, $E_{a}$ is the Arrhenius activation energy, and $R$ is the ideal gas constant. The above rate expression can be transformed into a non-isothermal rate expression describing the reaction rate as a function of temperature, at a constant heating rate, $\beta$ (Ramajo-Escalera et al., 2006):

$\frac{d \alpha}{d T}=\frac{A}{\beta} e^{\left(-E_{a} / R T\right)} f(\alpha)$

where $\beta$ is the heating rate. Various kinetic methods have been derived from Eq. (6). Generally, these can divided into integral methods, such as those of Ozawa (1965) and Flynn and Wall (1966), and differential methods such as those of Friedman (1964) and Kissinger (1957). The methods of Flynn and Wall (ASTM E 1641) and Kissinger were employed to calculate kinetic parameters in the present study.

\subsubsection{Kinetic method of Flynn and Wall (ASTM E 1641)}

The standard method to investigate decomposition kinetics by thermogravimetry (ASTM E 1641) is based on an integral isoconversional method proposed by Flynn and Wall (1966). To determine the kinetic parameters, Arrhenius activation energy and pre-exponential factor, it is assumed that the decomposition obeys first-order kinetics. In this isoconversional method, the temperature at which a fixed conversion $(\alpha)$ occurs is recorded. Then, Arrhenius activation energy can be calculated by using Eq. (7) as follows:

$E_{\mathrm{e}}=-\left(\frac{R}{b}\right) \frac{\Delta \log \beta}{\Delta(1 / T)}$

where $\beta(\mathrm{K} / \mathrm{min})$ is the heating rate, $E_{\mathrm{e}}(\mathrm{J} / \mathrm{mol})$ is the estimated Arrhenius activation energy, $b(1 / \mathrm{K})$ is an iteration variable with the first iteration being fixed at $0.457 / \mathrm{K}, R$ is the ideal gas constant $(8.314 \mathrm{~J} / \mathrm{K} \mathrm{mol})$ and $T(\mathrm{~K})$ is the absolute temperature at conversion $\alpha$.

A plot of $\log \beta$ versus $1 / T$ for each conversion level $(\alpha)$ should result in a straight line. The least-squares method was used to fit each straight line and determine the slope, $\Delta(\log \beta) / \Delta(1 / T)$. The estimated activation energy, $E_{\mathrm{e}}$, was then calculated by Eq. (7), making use of a value of $0.457 / \mathrm{K}$ for $b$ in the first iteration. The value, $E / R T_{\mathrm{c}}$, was calculated from the temperature, $T_{\mathrm{c}}$, at constant conversion for the heating rate closest to the midpoint of the experimental heating rates, i.e., $10 \mathrm{~K} / \mathrm{min}$. This initial value of $E / R T_{\mathrm{c}}$ was used to obtain a new estimate of $b$ from a table published by Doyle (1961). This procedure was repeated until the estimated activation energy 
Table 1

Chemical composition of the materials.

\begin{tabular}{|c|c|c|c|c|c|}
\hline Material & Cellulose (\%) & Hemicelluloses (\%) & Lignin (\%) & Ash (\%) & Extractives (\%) \\
\hline Depithed sugarcane bagasse & $49.49 \pm 0.31$ & $24.34 \pm 0.78$ & $22.69 \pm 0.08$ & $0.34 \pm 0.03$ & $1.8 \pm 0.67$ \\
\hline Prehydrolyzed depithed bagasse & $55.22 \pm 0.25$ & $17.54 \pm 0.22$ & $24.08 \pm 0.30$ & $0.59 \pm 0.05$ & - \\
\hline Bagasse cellulosic pulp & $88.32 \pm 0.07$ & $11.31 \pm 0.09$ & $1.45 \pm 0.07$ & $0.46 \pm 0.04$ & - \\
\hline
\end{tabular}

changed by less than $1 \%$. The refined value, $E_{\mathrm{r}}$, is reported as the Arrhenius activation energy.

The pre-exponential factor was calculated by using Eq. (8) as follows:

$A=-\left(\frac{\beta^{\prime}}{E_{\mathrm{r}}}\right) R \ln (1-\alpha) 10^{\mathrm{a}}$

where $\beta^{\prime}$ is the heating rate nearest the midpoint $(10 \mathrm{~K} / \mathrm{min}), E_{\mathrm{r}}$ $(\mathrm{J} / \mathrm{mol})$ is the refined Arrhenius activation energy, and $a$ is the value of an approximation of the temperature integral taken from Doyle's data for the refined value of $E_{\mathrm{e}} / R T_{\mathrm{c}}$.

\subsubsection{Kinetic method of Kissinger}

The Kissinger method is a differential isoconversional method used to obtain kinetic parameters such as Arrhenius activation energy, $E$, assuming $f(\alpha)=(1-\alpha)^{n}$ :

$\frac{d \alpha}{d T}=\left(\frac{A}{\beta}\right) e^{(-E / R T)}(1-\alpha)^{n}$

where $n$ is the reaction order.

The Kissinger method derives the activation energy from the temperature $\left(T_{m}\right)$ at which the maximum reaction rate (DTG peak) occurs and the reaction order from the shape of the mass loss-time curve (Jiang et al., 2010; Kissinger, 1957).

The activation energy, $E$, is obtained by plotting $\ln \left(\beta / T_{m}{ }^{2}\right)$ against $1 / T_{m}$. The slope, $\Delta\left[\ln \left(\beta / T_{m}^{2}\right)\right] / \Delta\left(1 / T_{m}\right)$, being equal to $-E / R$. The reaction order, $n$, is obtained from Eq. (10):

$n=1.26 S^{1 / 2}$

where $S$ is defined by Eq. (11). The value of $S$, the shape index, can be calculated from the time derivative of the DTG curve (second derivative of mass loss-time curve), as follows:

$S=\left|\frac{\left(d^{2} \alpha / d t^{2}\right)_{1}}{\left(d^{2} \alpha / d t^{2}\right)_{2}}\right|$

where subscripts 1 and 2 refer to the values of these quantities at the inflection points, i.e., where $\mathrm{d}^{3} \alpha / \mathrm{d} t^{3}=0$. The pre-exponential factor, $A$, can be obtained by inserting the values of $n$ and $E$ in Eq. (9) and solving it.

\section{Results and discussion}

The chemical composition of depithed bagasse, prehydrolyzed depithed bagasse and cellulose pulp was determined using TAPPI standard methods and is shown in Table 1 . As can be seen in Table 1 , the cellulose pulp used in the batch acid hydrolysis experiments presents minimal quantity of lignin and low hemicelluloses and ash contents.

Soda-anthraquinone cellulose pulp obtained from depithed sugarcane bagasse was hydrolyzed at 190,210 and $225^{\circ} \mathrm{C}$ in $0.07 \%$ $\mathrm{H}_{2} \mathrm{SO}_{4}(\mathrm{w} / \mathrm{v})$ for various times. After the reaction time, the reactor was quenched in an ice bath and the residual cellulose pulp was separated from the hydrolysate by filtration on a sintered glass funnel. The residual pulp was washed and dried at $60^{\circ} \mathrm{C}$ under reduced pressure for $24 \mathrm{~h}$ and the weight loss after hydrolysis was measured. The number- and weight-average degrees of polymerization were measured by gel permeation chromatography (GPC). The crystallinity index was calculated by the Segal method (Segal et al., 1959) and crystallite size was calculated for the three main crystal reflections $(\overline{110}, 110$ and 200$)$ by means of the Scherrer equation. The starting cellulose pulp and the residues after hydrolysis were subjected to dynamic thermogravimetric analysis under a nitrogen atmosphere at four different heating rates, in order to determine the effects of hydrolysis time, temperature, degree of polymerization and crystallite size on thermal decomposition of cellulose. In the following section the main results will be discussed.

\subsection{Thermogravimetric analysis (TGA)}

Dynamic thermogravimetric curves (TG) at four heating rates and their first derivative curves (DTG), for the starting cellulose pulp and samples hydrolyzed at 190,210 and $225^{\circ} \mathrm{C}$ for 80,40 and $8 \mathrm{~min}$, are shown in Fig. $1(\mathrm{a}-\mathrm{d})$. As can be seen, these curves are generally similar to those reported in the literature (Bouchard et al., 1989, 1990; Calahorra et al., 1989; Kim et al., 2010; Poletto et al., 2011). The initial small weight loss, which occurred at temperatures below $100{ }^{\circ} \mathrm{C}$, represented $5 \%$ of the total weight loss on average and was attributed to the vaporization of bound water in the samples. For all samples, this initial weight loss was followed by a plateau that extended to the start of the main decomposition event causing weight loss. As can be seen in Table 2, the onset temperature ( $\left.T_{\text {onset }}\right)$, which indicates thermal stability, decreased as hydrolysis time increased for cellulose residues obtained after acid catalyzed hydrolysis at $190^{\circ} \mathrm{C}$ in comparison with original cellulose pulp. For cellulose residues obtained after hydrolysis at $210^{\circ} \mathrm{C}$ and $225^{\circ} \mathrm{C}$, the $T_{\text {onset }}$ initially decreased as hydrolysis time increased in comparison with original cellulose pulp and after which it was practically constant as hydrolysis time increased.

According to Shafizadeh (1985), the main decomposition event consists of the depolymerization of cellulose to various anhydrosugar derivatives and their volatilization. The mechanism of cellulose decomposition was recently elucidated by Shen and $\mathrm{Gu}$ (2009), who studied cellulose pyrolysis in a thermogravimetric analyzer coupled to the FTIR spectrophotometer. According to Shen and $\mathrm{Gu}$ (2009), the main component detected was levoglucosan (1,6-anhydro- $\beta$-D-glucopyranose). After the main decomposition event, a third event began, and the rate of weight loss was not constant. Bouchard et al. (1989) attributed this event to the slow combustion of the charred fraction, which is inhibited in a nitrogen atmosphere.

The differences in the decomposition profiles of the original cellulose pulp and its residues after dilute acid hydrolysis at 190, 210 and $225^{\circ} \mathrm{C}$ for 80,40 and $8 \mathrm{~min}$, respectively, indicate the differences in initial decomposition temperature of these samples. In the following sections, the influence of degree of polymerization, crystallinity index and crystallite size will be discussed in detail.

\subsection{Influence of degree of polymerization}

Table 2 shows the percentage of remaining pulp after dilute acid hydrolysis in $0.07 \% \mathrm{H}_{2} \mathrm{SO}_{4}(\mathrm{w} / \mathrm{v})$ at 190,210 and $225^{\circ} \mathrm{C}$, numberand weight-average degrees of polymerization $\left(\mathrm{DP}_{n}\right.$ and $\left.\mathrm{DP}_{w}\right)$, crystalline index (CrI), crystallite size in the $\overline{110}, 110$ and 200 planes, initial $\left(T_{i}\right)$, maximum $\left(T_{m}\right)$ and final $\left(T_{f}\right)$ temperatures for the main decomposition event, char yield and activation energy $\left(E_{a}\right)$ and preexponential factor calculated using the ASTM E 1641 and Kissinger 

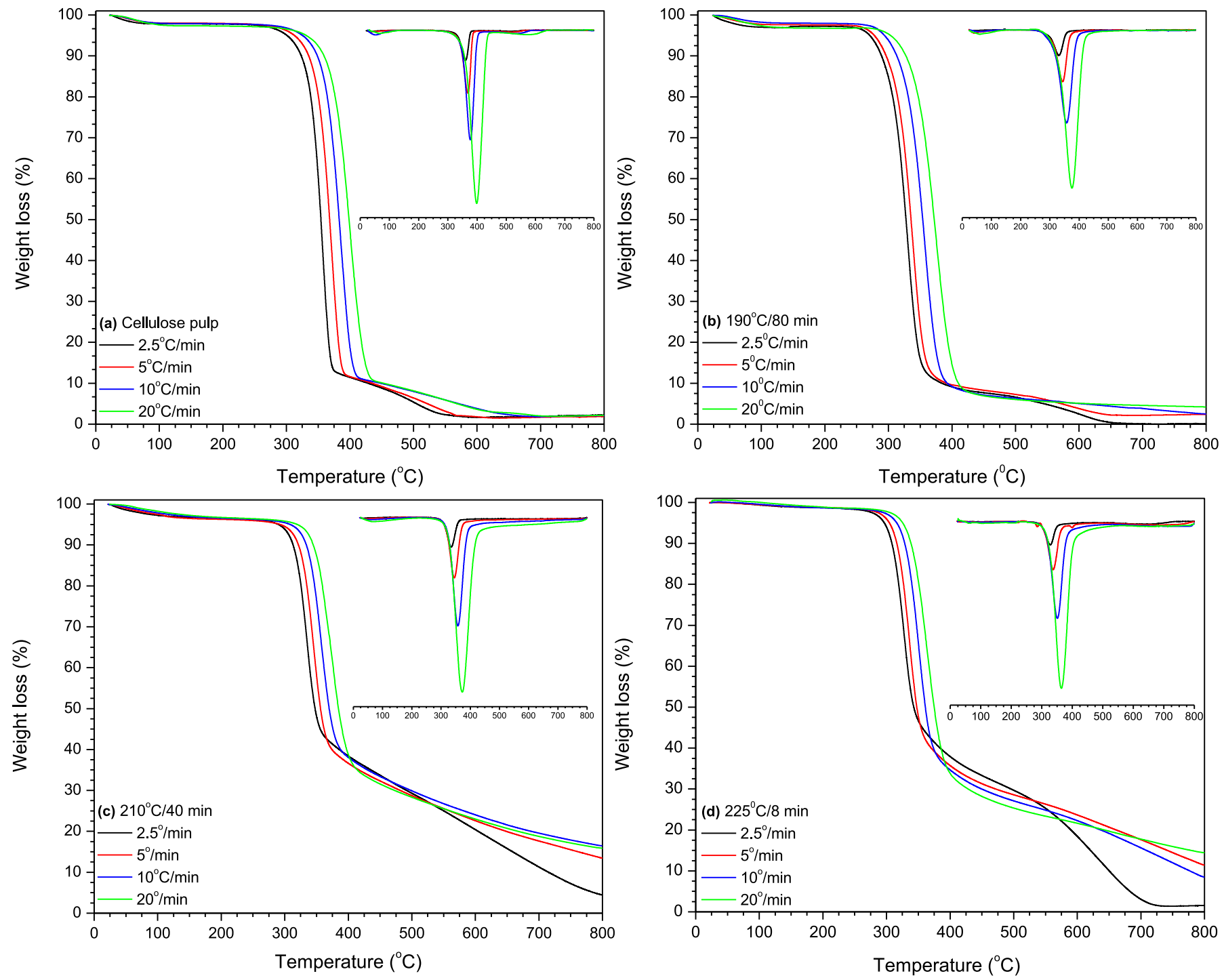

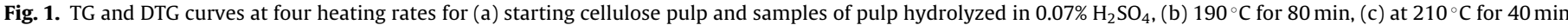
and (d) at $225^{\circ} \mathrm{C}$ for $8 \mathrm{~min}$.

methods. The effect of number- and weight-average degrees of polymerization on the thermal decomposition of cellulose can be analyzed in more detail from Fig. 2, which shows $T_{i}, T_{m}$ and $T_{f}$ as a function of $\mathrm{DP}_{n}$ and $\mathrm{DP}_{w}$.

It can be seen in Table 2 and Fig. 2, for cellulose residues hydrolyzed at $190,210^{\circ} \mathrm{C}$ and $225^{\circ} \mathrm{C}$, that $T_{i}$, which indicates the initial decomposition temperature, initially increased as numberand weight-average degrees of polymerization decreased, reaching a maximum value, after which it began to decrease for all reaction temperatures studied. Besides, the initial increase in $T_{i}$ was lower as the reaction temperature was increased from 190 to $225^{\circ} \mathrm{C}$. These results indicate that the more severe the acid hydrolysis, the less resistant is the cellulose residue to thermal decomposition.

From the derivative thermogravimetric curves (DTG) (Fig. 1), $T_{m}$ values were determined as those temperatures at which the rate of decomposition reaches its maximum value. As can be seen in Table 2 and Fig. 2, $T_{m}$ decreased as $\mathrm{DP}_{n}$ and $\mathrm{DP}_{w}$ decreased for all reaction temperatures; in other words, peak decomposition temperatures were shifted to lower values with falling $\mathrm{DP}_{n}$ and $\mathrm{DP}_{w}$. However, $T_{f}$ values increased as $\mathrm{DP}_{n}$ and $\mathrm{DP}_{w}$ decreased, reaching a maximum value, for cellulose hydrolyzed at 210 and $225^{\circ} \mathrm{C}$, and beyond this maximum value a small decrease was observed. For hydrolysis at $190^{\circ} \mathrm{C}, T_{f}$ increased as $\mathrm{DP}_{n}$ and $\mathrm{DP}_{w}$ decreased, reaching a maximum at the lowest values of $\mathrm{DP}_{n}$ and $\mathrm{DP}_{w}$. Besides, $T_{f}$ exhibited a higher rate of increase with decreasing $\mathrm{DP}_{n}$ and $\mathrm{DP}_{w}$ as the reaction temperature was increased from 190 to $225^{\circ} \mathrm{C}$. In Table 2 it may be noted that the charred fraction increased as $\mathrm{DP}_{n}$ and $\mathrm{DP}_{w}$ decreased and also as the reaction temperature was increased. This increase in the charred fraction becomes more marked as the reaction temperature was increased and consequently as $\mathrm{DP}_{n}$ and $\mathrm{DP}_{w}$ became more reduced. These results suggest that cellulose decomposes at a lower temperature and that char formation is favored by falling $\mathrm{DP}_{n}$ and $\mathrm{DP}_{w}$.

Similar results were observed by Calahorra et al. (1989), who studied the effect of molecular weight on thermal decomposition of cellulose, and by Bouchard et al. (1989, 1990), who studied the thermal behavior of depolymerized cellulose residues produced by dilute acid hydrolysis in $0.4 \% \mathrm{H}_{2} \mathrm{SO}_{4}$ at $190^{\circ} \mathrm{C}$ for various periods of time and thermo-mechanical treatment at high temperature, using ethylene glycol as solvent. According to Bouchard, severe hydrolysis produces cellulose more resistant to thermal degradation. Bouchard based his observation on the results obtained from 

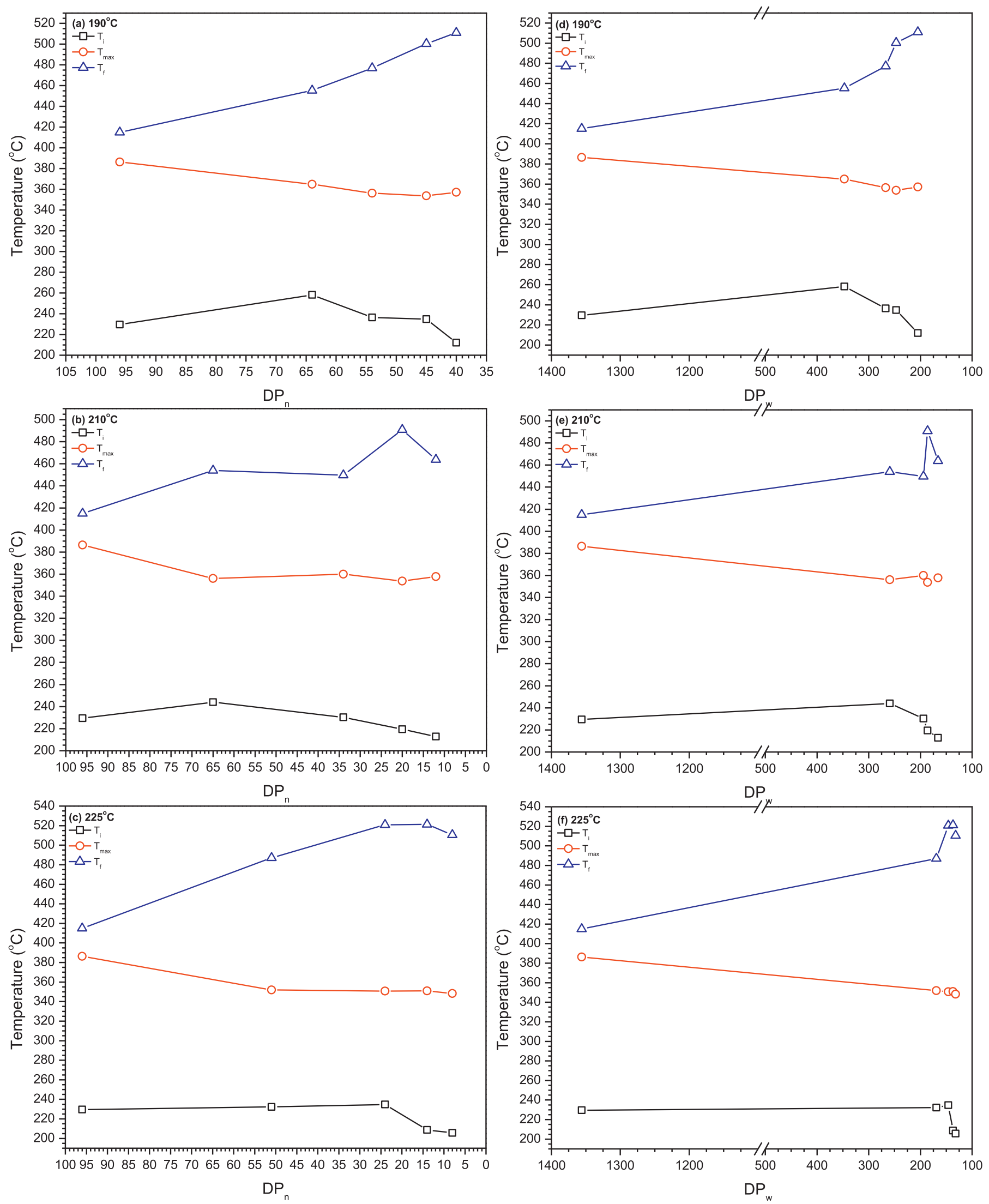

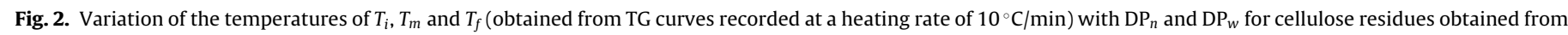
dilute acid hydrolysis $\left(0.07 \% \mathrm{H}_{2} \mathrm{SO}_{4}\right)$ at $190^{\circ} \mathrm{C}(\mathrm{a})$ and $(\mathrm{d}), 210^{\circ} \mathrm{C}(\mathrm{b})$ and (e) and $225^{\circ} \mathrm{C}(\mathrm{c})$ and (f). 


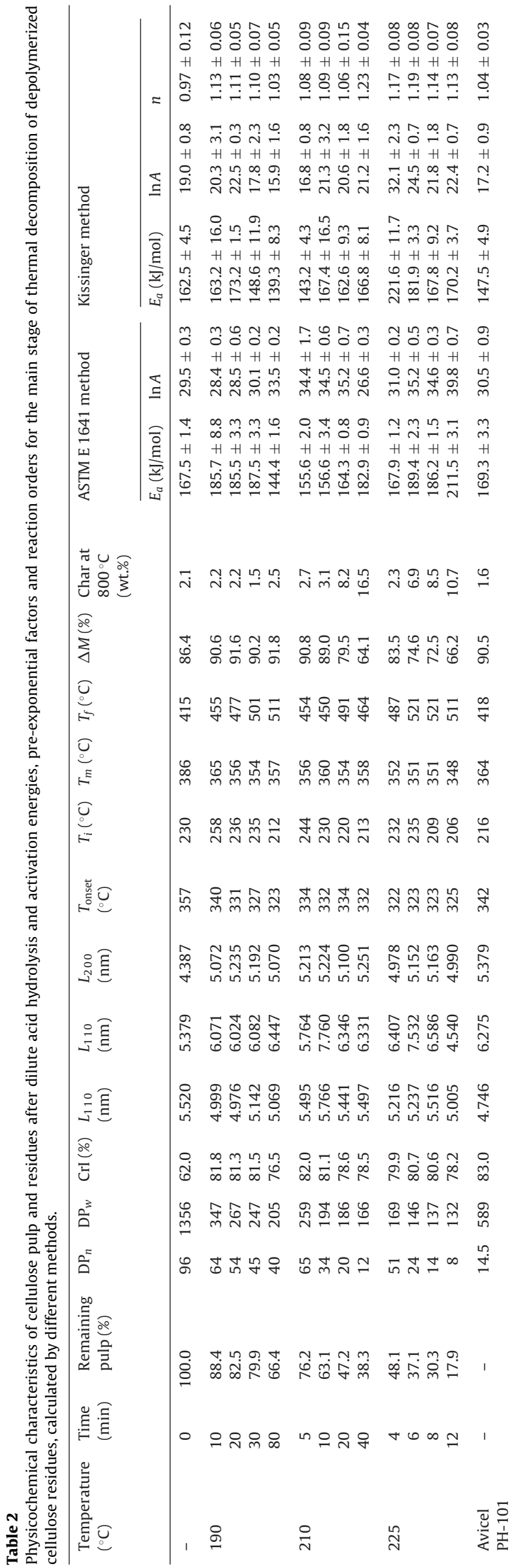

analytical techniques such as TG, DSC, FTIR and DRIFTS and concluded that the additional resistance to thermal decomposition was provided by important structural and/or chemical rearrangements of the cellulose during acid hydrolysis.

Comparing the temperatures $T_{i}, T_{m}$ and $T_{f}$ obtained for Avicel PH-101 and bagasse cellulose samples hydrolyzed at 190, 210 and $225^{\circ} \mathrm{C}$ for 80,40 and $8 \mathrm{~min}$, respectively, it can be seen that the temperatures $T_{i}$ and $T_{m}$ for these cellulose residues were close to those of Avicel and that $T_{f}$ alone deviates. To a first approximation, these results suggest that these cellulose residues exhibited similar thermal decomposition behavior to that of Avicel.

The kinetics of thermal decomposition of the cellulose pulp and residues after acid hydrolysis was analyzed by the methods of Flynn and Wall (ASTM E 1641) and Kissinger. Table 2 shows the resulting activation energies $\left(E_{a}\right)$, pre-exponential factors $(A)$ and reaction orders ( $n$ ). Fig. 3 shows the activation energies calculated by the ASTM and Kissinger methods, plotted against $\mathrm{DP}_{n}$ and $\mathrm{DP}_{w}$. According to the ASTM method, thermal decomposition obeys first-order kinetics. For the hydrolysis temperature of $190^{\circ} \mathrm{C}$, the activation energy calculated by this method initially increased as $\mathrm{DP}_{n}$ and $\mathrm{DP}_{w}$ decreased and achieved a maximum value, after which it fell sharply. For $210^{\circ} \mathrm{C}$, the activation energy initially decreased as $\mathrm{DP}_{n}$ and $\mathrm{DP}_{w}$ decreased, reaching a minimum, after which it increased as $\mathrm{DP}_{n}$ and $\mathrm{DP}_{w}$ decreased. For $225^{\circ} \mathrm{C}$, the activation energy was practically constant from the highest $\mathrm{DP}_{n}(96)$ and $\mathrm{DP}_{w}$ (1356) down to 51 and 169. At lower molecular weights, the activation energy increased to a maximum of $211.5 \mathrm{~kJ} / \mathrm{mol}$. This value of activation energy was the highest observed for all hydrolysis temperatures studied, by the ASTM method.

Employing the Kissinger method, it was possible to calculate the reaction orders for the thermal decomposition of cellulose pulp and residues after acid hydrolysis. The reaction orders $(n)$ showed some variation with $\mathrm{DP}_{n}$ and $\mathrm{DP}_{w}$. The lower value of $n$ was obtained with the starting cellulose pulp (0.97). For the cellulose residues, $n$ varied from 1.03 to 1.23 . These values of reaction order indicate that both cellulose pulp and the residues with reduced $\mathrm{DP}_{n}$ and $\mathrm{DP}_{w}$ after acid hydrolysis obeyed first-order decomposition kinetics, confirming that the ASTM method can be used to calculate kinetic parameters of cellulose decomposition. For the hydrolysis temperature of $190^{\circ} \mathrm{C}$, the activation energy calculated by the Kissinger method was constant from $\mathrm{DP}_{n}$ and $\mathrm{DP}_{w}$ of 96 and 1356 to 64 and 347 , respectively, at lower values of $\mathrm{DP}_{n}$ and $\mathrm{DP}_{w}$, the activation energy increased to a maximum and after which it fell sharply. For $210^{\circ} \mathrm{C}$, the activation energy decreased as $\mathrm{DP}_{n}$ and $\mathrm{DP}_{w}$ decreased, to reach a minimum value, after which it increased sharply and then remained practically constant. For $225^{\circ} \mathrm{C}$, the activation energy increased sharply as $\mathrm{DP}_{n}$ and $\mathrm{DP}_{w}$ decreased, achieving a maximum value and then decreasing rapidly.

The activation energies for thermal degradation of cellulose residues hydrolyzed at 190,210 and $225^{\circ} \mathrm{C}$ for 80,40 and $8 \mathrm{~min}$, calculated by the ASTM and Kissinger methods, differed by $17.2 \%$, $8.0 \%$ and $10.0 \%$, and $5.6 \%, 13.1 \%$ and $13.8 \%$, from those obtained for Avicel PH-101, respectively. Considering the observed temperatures $T_{i}$ and $T_{m}$ and the activation energies obtained by the ASTM and Kissinger methods, it may be suggested that cellulose residues obtained by ELA hydrolysis at 190,210 and $225^{\circ} \mathrm{C}$ for 80,40 and 8 min presented similarities with Avicel. Subsequent interpretation of the crystalline index and crystallite size in the next section will confirm this result. One important point to emphasize is that the comparisons of the physicochemical properties of the cellulose residues and Avicel have to take into consideration the differences by which each material is obtained. Furthermore, the possibility of using these residues in commercial applications is a matter of great interest in the field of biofuels and biomaterials.

Comparing the values of $E_{a}$ obtained by the two analytical methods, it can be observed that activation energies calculated by the 

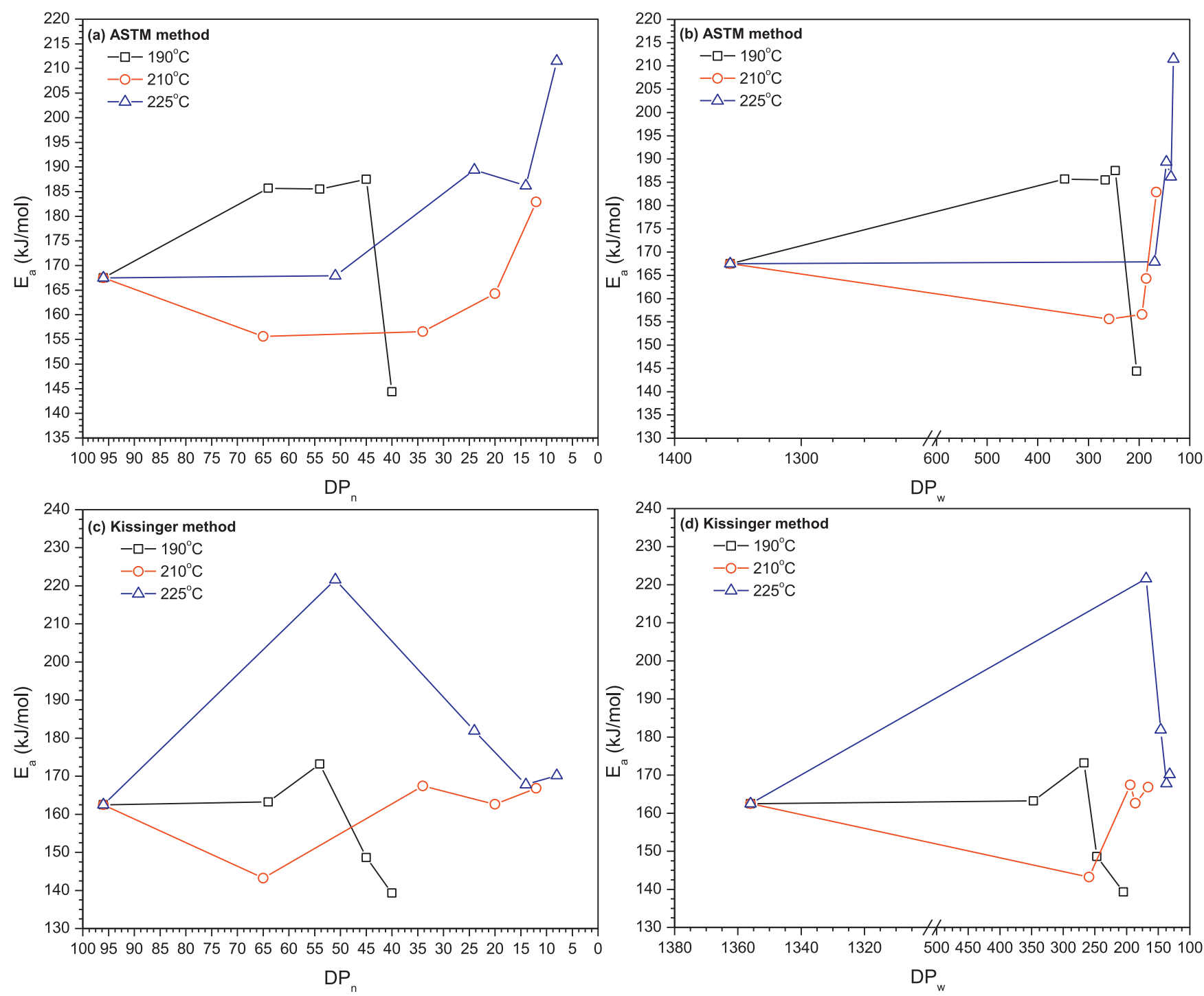

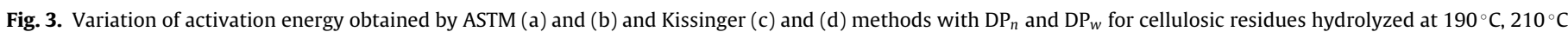
and $225^{\circ} \mathrm{C}$.

ASTM method were in general higher than those calculated by Kissinger method. Nonetheless, for hydrolysis temperatures of 190 and $210^{\circ} \mathrm{C}$, similar profiles were observed, while for $225^{\circ} \mathrm{C}$, contrasting behavior was noted. The increase in activation energy as the degree of polymerization falls was also observed by Calahorra et al. (1989). Supplementary Table 1 shows the values of activation energy calculated by Calahorra et al. (1989) for cellulose samples containing various degrees of polymerization and crystallinity indices, employing the Freeman-Carroll and Broido methods. When the results obtained in this study are compared with those obtained by Calahorra et al. (1989), it is notable that the reaction order decreased as the degree of polymerization decreased in the cellulose samples prepared by Calahorra et al. (1989), whereas in this study the reaction order showed little variation, from 1.03 to 1.23. Thus, the fall in the activation energies calculated by the FreemanCarroll and Broido methods, as degree of polymerization decreased, was greater than that obtained in this study.

\subsection{Influence of crystallinity and crystallite size}

As can be seen in Table $2, T_{i}$ initially increased as the crystallinity index and crystallite size in the 110 and 200 planes increased, for cellulose samples hydrolyzed at 190,210 and $225^{\circ} \mathrm{C}$. These results suggest that an increase in the crystallinity index and crystallite size increases the initial decomposition temperature of the cellulose residues. This increase in the crystallinity index and crystallite size (in the 110 and 200 planes) may be related to the diminution in the amorphous cellulose region that was accompanied by weight losses of $11.6 \%, 23.8 \%$ and $51.9 \%$ in the first stages of the dilute acid hydrolysis at 190,210 and $225^{\circ} \mathrm{C}$, respectively. Kim et al. (2010) studied various cellulose samples and noticed that an increase in the crystallinity index and crystallite size provided higher thermal stability. Poletto et al. (2011) also studied cellulose pulp obtained by two pulping processes and observed a displacement of the DTG peak to higher temperatures with increasing crystallite size.

In Table 2, it is possible to observe that, for samples hydrolyzed at 190 and $225^{\circ} \mathrm{C}$, the activation energies calculated by both the ASTM and Kissinger methods increased as crystallinity and crystallite size increased. For $210^{\circ} \mathrm{C}$, the influence of crystallinity and crystallite size was not so clear. Kim et al. (2010) reported that the activation energy was not affected by the crystallinity index or crystallite size.

The crystalline index and crystallite sizes (in the $\overline{110}, 110$ and 200 planes) of cellulose residues hydrolyzed at 190, 210 and 

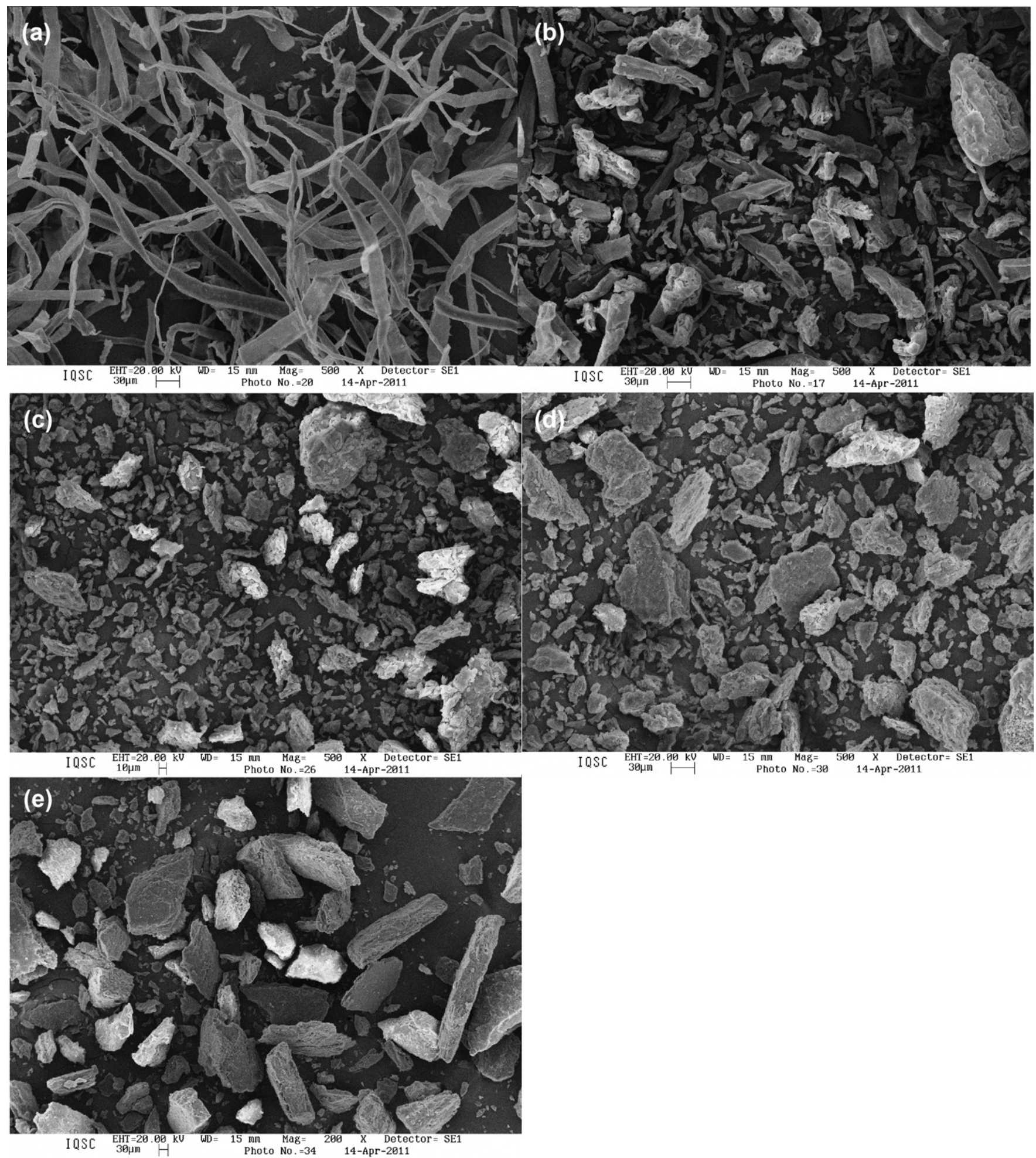

Fig. 4. SEM micrographs of (a) bagasse cellulose pulp, (b) Avicel PH-101, and (c) pulp hydrolyzed at $190^{\circ} \mathrm{C}$ for $80 \mathrm{~min}$, (d) at $210{ }^{\circ} \mathrm{C}$ for $40 \mathrm{~min}$ and (e) at $225^{\circ} \mathrm{C}$ for 8 min.

$225^{\circ} \mathrm{C}$ for 80,40 and 8 min were similar to Avicel PH-101. CrI for these residues differed by $8.5 \%, 5.7 \%$ and $3.0 \%$ from Avicel and the crystallite size differed by $2.7 \%, 0.9 \%$ and $5.0 \%$ for the 110 plane and $6.1 \%, 2.4 \%$ and $7.8 \%$ for the 200 plane, whereas for the unhydrolyzed bagasse cellulose pulp, CrI differed by $33.9 \%$ and crystallite sizes by $16.7 \%$ ( 110 ) and $22.6 \%$ (200). These results, in addition to those obtained from the degree of polymerization, thermal analysis and kinetic decomposition studies, also indicate that the cellulose residues processed by ELA hydrolysis at 190,210 and $225^{\circ} \mathrm{C}$ have similar physicochemical characteristics to Avicel PH-101. Therefore, it is suggested that these cellulose residues, representing up to $20 \%$ of the starting sugarcane bagasse feedstock (on dry basis) may be used in various commercial applications as microcrystalline cellulose (MCC). This finding represents a potential novel use of the 
cellulose residues of the dilute acid hydrolysis process, which may become an important product in a biorefinery with various applications in developing green materials (Das et al., 2010) and as a precursor in the production of whiskers (nanocrystalline cellulose), with almost no weight loss (Das et al., 2009).

\subsection{Scanning electron microscopy (SEM)}

Fig. 4 shows SEM micrographs of bagasse cellulose pulp, Avicel $\mathrm{PH}-101$ and samples hydrolyzed at 190,210 and $225^{\circ} \mathrm{C}$ for 80 , 40 and $8 \mathrm{~min}$, respectively. Fig. 4a shows the bagasse pulp fibers in their initial condition. In this figure, the fibers exhibit a great variety of shapes and sizes, characterizing the great heterogeneity of the bagasse pulp. Fig. 4b shows Avicel PH-101, a commercial microcrystalline cellulose, which is mainly composed of particles that have a rod-shaped fibers. Fig. 4c-e shows cellulose residues hydrolyzed at 190,210 and $225^{\circ} \mathrm{C}$. For $190^{\circ} \mathrm{C}$ (Fig. 4c), the particles exhibited smaller length/width ratio than Avicel and it is apparent that shortening of the fibers took place, giving smaller elements. For $210^{\circ} \mathrm{C}$ (Fig. $4 \mathrm{~d}$ ), the particles seem to be larger and more fragmented than for $190^{\circ} \mathrm{C}$ and Avicel, but large fragments can still be observed. For $225^{\circ} \mathrm{C}$ (Fig. 4e), the particles seem to be rod-shaped like Avicel, but much larger than Avicel, and flat elements can also be observed.

Particle size was measured with Image-Pro Plus ${ }^{\mathrm{TM}} 6.0$ software. On average, a sample of one hundred particles was collected and analyzed statistically with Statistica ${ }^{\mathrm{TM}} 7.0$ software. Supplementary Fig. 1 shows the particle length distributions of four samples, Avicel PH-101 and the bagasse pulp samples hydrolyzed at $190,210,225^{\circ} \mathrm{C}$ for 80,40 and $8 \mathrm{~min}$, respectively. The particle length distributions were best fitted by the lognormal distribution function. As can be seen in Supplementary Fig. 1, higher hydrolysis temperatures and shorter reaction times produced longer particles. Furthermore, higher temperatures and shorter reaction times produced particles more heterogeneous in size, which can be seen from the increasing widths of the distributions. From Supplementary Fig. 1 it can be concluded that the cellulose residue hydrolyzed at $190^{\circ} \mathrm{C}$ for 80 min exhibited smaller particles than Avicel and that the latter showed particles smaller than the cellulose residues hydrolyzed at 210 and $225^{\circ} \mathrm{C}$ for 40 and $8 \mathrm{~min}$, respectively. Avicel PH-101 exhibited a particle length of $87.5 \pm 34.2 \mu \mathrm{m}$, while cellulose residues hydrolyzed at 190,210 and $225^{\circ} \mathrm{C}$ exhibited particle lengths of $38.0 \pm 20.1,213.2 \pm 97.1$ and $347.6 \pm 114.4 \mu \mathrm{m}$, respectively.

The above morphology and particle size analysis leads to the conclusion that cellulose residues hydrolyzed at 190 and $210^{\circ} \mathrm{C}$ exhibited particle lengths similar to Avicel, while hydrolysis at $225^{\circ} \mathrm{C}$ produced much larger particles.

\subsection{Fourier transform infrared spectroscopy (FTIR)}

The FTIR spectra of cellulose pulp and samples hydrolyzed in $0.07 \% \mathrm{H}_{2} \mathrm{SO}_{4}(\mathrm{w} / \mathrm{v})$ at $190^{\circ} \mathrm{C}, 210^{\circ} \mathrm{C}$ and $225^{\circ} \mathrm{C}$ are given in Fig. 5 . According to Bouchard et al. (1989), the appearance of a band around $1710 \mathrm{~cm}^{-1}$ is attributed to carbonyl formation on cellulose. In the cellulose samples hydrolyzed at 210 and $225^{\circ} \mathrm{C}$, a band appeared at $1708 \mathrm{~cm}^{-1}$ and increased in intensity as reaction time and temperature were increased. According to Bouchard et al. (1989), as the leveling-off degree of polymerization (LODP) is reached, this band appears. All the bands related to $\mathrm{CH}$ and/or $\mathrm{CH}_{2}$ vibrations at $1430,1370,1315$ and $895 \mathrm{~cm}^{-1}$ decreased in intensity or almost disappeared as the reaction temperature was increased from $190^{\circ} \mathrm{C}$ to $225^{\circ} \mathrm{C}$. According to Bouchard et al. (1989), a decreasing intensity or disappearance of these bands indicates an increase in the degree of oxidation. All the bands attributed to $\mathrm{OH}$ bending at 1455,1336 and $1203 \mathrm{~cm}^{-1}$ are reduced in intensity. The bands at $1162,1115,1058$ and $1035 \mathrm{~cm}^{-1}$, related to
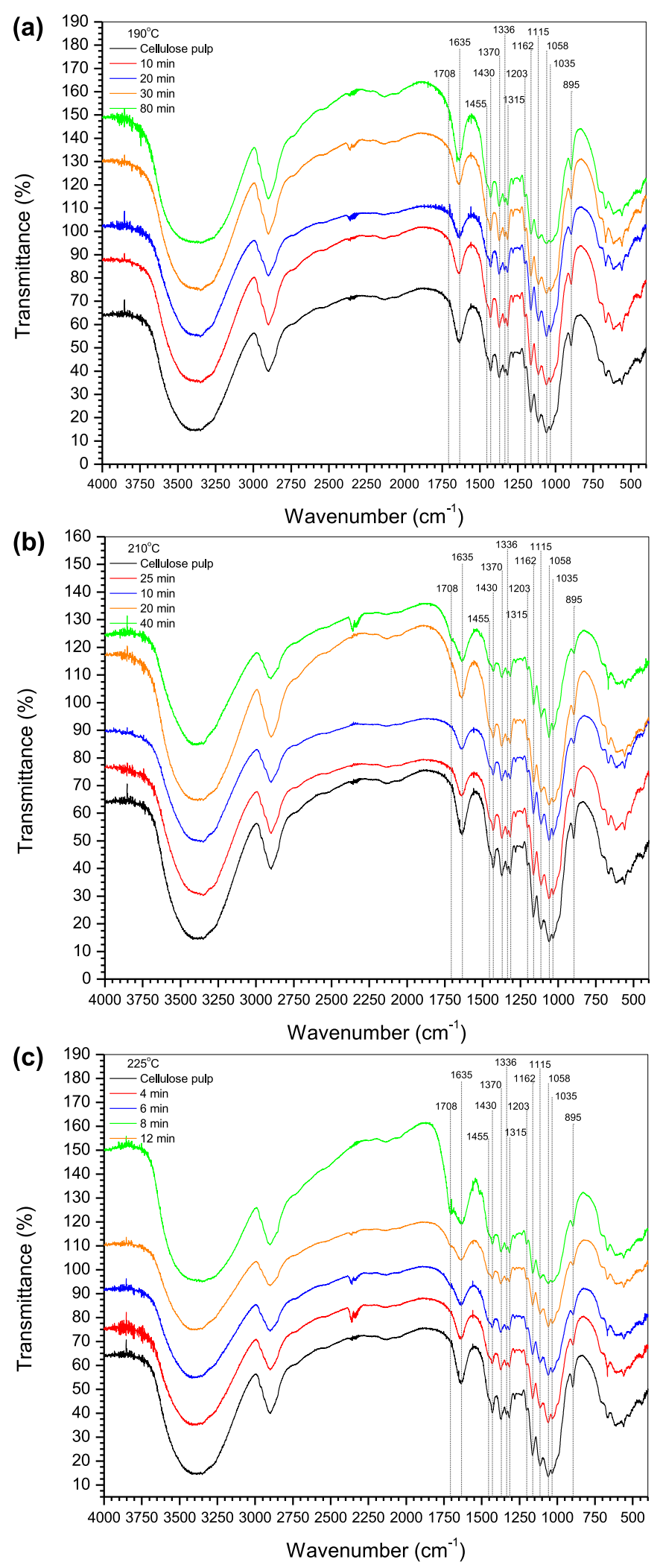

Fig. 5. FTIR spectra of cellulose pulp and residues hydrolyzed at (a) $190^{\circ} \mathrm{C}$, (b) $210^{\circ} \mathrm{C}$ and (c) $225^{\circ} \mathrm{C}$ for various times. 
asymmetric $\mathrm{C}-\mathrm{O}-\mathrm{C}$ bridge stretching, anhydroglucopyranose ring, $\mathrm{C}-\mathrm{OR}$ stretching and $\mathrm{C}-\mathrm{O}-\mathrm{C}$ pyranose ring skeletal vibration (Poletto et al., 2011), were unaltered and/or strengthened as reaction time was increased for all temperatures. Only for a long reaction time, such as $80 \mathrm{~min}\left(190^{\circ} \mathrm{C}\right)$, and/or the highest temperature $\left(225^{\circ} \mathrm{C}\right)$ and a reaction time of $12 \mathrm{~min}$, was a fall in intensity of the bands at 1058 and $1035 \mathrm{~cm}^{-1}$ observed. According to Bouchard et al. (1989), these observations indicate that the pyranose ring is almost unchanged.

It can be concluded that the intensity of the carbonyl bands followed the extent of cellulose depolymerization, which is correlated with the number- and weight-average degrees of polymerization of cellulose residues, especially at higher temperatures. FTIR spectra of cellulose residues also indicated that the degree of chemical modification of cellulose increases with the severity of hydrolysis.

\subsection{Comparison with bagasse microcrystalline cellulose (MCC) in literature}

Tang et al. (1996) prepared MCC by treating bagasse pulp with $2.5 \mathrm{~mol} / \mathrm{L} \mathrm{HCl}$ at $105^{\circ} \mathrm{C}$ for $15 \mathrm{~min}$. This MCC from bagasse was characterized by XRD and SEM, and the DP was determined by measuring the intrinsic viscosity of the cellulose in a cuproethylenediamine solution. The crystallinity index was found to be $72 \%$, crystallite size in the 101 and 200 lattice planes was 4.9 and $5.5 \mathrm{~nm}$ and $\mathrm{DP}_{v}$ was 117. El-Sakhawy and Hassan (2007) prepared MCC from bleached bagasse pulp by treating with $2 \mathrm{~N}$ $\mathrm{HCl}$ and/or $\mathrm{H}_{2} \mathrm{SO}_{4}$ under reflux for $45 \mathrm{~min}$, employing a solid-toliquid ratio of $1: 10$, and characterized it by XRD, TGA, SEM and DP. Again DP was measured by intrinsic viscosity in cuprammonium hydroxide solution. Crystallinity was found to be $76 \%$ and $75 \%$, crystallite size in the 200 plane was $4.42 \mathrm{~nm}$ and $\mathrm{DP}_{v}$ was 317 and 299 for $\mathrm{HCl}$ and $\mathrm{H}_{2} \mathrm{SO}_{4}$, respectively. $T_{i}$ and $T_{m}$ were determined by TGA carried out at a heating rate of $10^{\circ} \mathrm{C} / \mathrm{min}$ under a nitrogen atmosphere and were found to be 251 and $252^{\circ} \mathrm{C}$ for $\mathrm{HCl}$ and 325 and $322{ }^{\circ} \mathrm{C}$ for $\mathrm{H}_{2} \mathrm{SO}_{4}$, respectively. For comparison, the cellulose residues hydrolyzed at 190,210 and $225^{\circ} \mathrm{C}$ for 80,40 and 8 min showed crystalline indices of $76.5 \%, 78.5 \%$ and $80.6 \%$, respectively, and crystallite size in 101 and 200 planes of 6.082 and $5.070 \mathrm{~nm}$ for $190^{\circ} \mathrm{C}, 6.331$ and $5.251 \mathrm{~nm}$ for $210^{\circ} \mathrm{C}$ and 4.540 and $4.990 \mathrm{~nm}$ for $225^{\circ} \mathrm{C}$, which compare well with those obtained by Tang et al. (1996) and El-Sakhawy and Hassan (2007), by traditional methods. $\mathrm{DP}_{n}$ and $\mathrm{DP}_{w}$ were found to be 40 and 205 for $190^{\circ} \mathrm{C}, 12$ and 166 for $210^{\circ} \mathrm{C}$ and 14 and 137 for $225^{\circ} \mathrm{C}$ in this study. Considering that the difference between $\overline{M_{v}}$ and $\overline{M_{w}}$ depends on sample molar mass distribution and $\overline{M_{w}}>\overline{M_{v}}$, it is possible to conclude that the degree of polymerization of MCC prepared by Tang et al. (1996) is close to that of the cellulose residues obtained in this study. $T_{i}$ and $T_{m}$ were found to be 212 and 357 for $190^{\circ} \mathrm{C}, 213$ and 358 for $210^{\circ} \mathrm{C}$ and 206 and 348 for $225^{\circ} \mathrm{C}$, quite similar to those observed by ElSakhawy and Hassan (2007). From the above comparisons between literature data and the cellulose residues obtained in this study, it is possible to state that cellulose residues hydrolyzed at 190,210 and $225^{\circ} \mathrm{C}$ for 80,40 and $8 \mathrm{~min}$ can be considered as microcrystalline celluloses.

\section{Conclusion}

This study showed that the initial decomposition temperature $\left(T_{i}\right)$ of cellulose residues after extremely low acid hydrolysis (ELA) increased as the degree of polymerization decreases and that this rise in $T_{i}$ diminished as hydrolysis became more severe by increasing the reaction temperature from 190 to $225^{\circ} \mathrm{C}$. Activation energies determined by the ASTM and Kissinger methods demonstrated that the severity of hydrolysis directly affects the energy involved in the main decomposition step of the cellulose residues. Furthermore, XRD studies also showed that initial decomposition temperature $\left(T_{i}\right)$ increased as crystalline index and crystallite size in the 110 and 200 lattice planes increased. The thermal, XRD and SEM studies demonstrated that the cellulose residues obtained at 190,210 and $225^{\circ} \mathrm{C}$ for 80,40 and $8 \mathrm{~min}$, respectively, have similar thermal decomposition behavior, crystallinity index, crystallite size and particle size to Avicel PH-101 and can also be considered microcrystalline celluloses.

\section{Acknowledgements}

The authors are grateful to Conselho Nacional de Pesquisa e Desenvolvimento (CNPq), Fundação de Amparo à Pesquisa do Estado de São Paulo (FAPESP) and Oxiteno for providing financial support for this research. The authors also thank the Instituto de Química de São Carlos (IQSC), USP at São Carlos (SP, Brazil).

\section{Appendix A. Supplementary data}

Supplementary data associated with this article can be found, in the online version, at doi:10.1016/j.indcrop.2011.11.009.

\section{References}

Bouchard, J., et al., 1989. Characterization of depolymerized cellulosic residues 1. Residues obtained by acid-hydrolysis processes. Wood Sci. Technol. 23 (4) 343-355.

Bouchard, J., et al., 1990. Characterization of depolymerized cellulosic residues. 2. Residues derived from ethylene-glycol solvolysis of cellulose. Wood Sci. Technol. 24 (2), 159-169.

Bradbury, A.G.W., et al., 1979. Kinetic-model for pyrolysis of cellulose. J. Appl. Polym. Sci. 23 (11), 3271-3280.

Broido, A., Nelson, M.A., 1975. Char yield on pyrolysis of cellulose. Combust. Flame 24 (2), 263-268.

Calahorra, M.E., et al., 1989. Thermogravimetric analysis of cellulose - effect of the molecular-weight on thermal-decomposition. J. Appl. Polym. Sci. 37 (12), 3305-3314.

CONAB. 2010. Companhia Nacional de Abastecimento. Avaliação da safra agrícola brasileira de cana-de-açúcar, safra 2010, segundo levantamento, Setembro. (in Portuguese).

Das, K., et al., 2009. A study of the mechanical, thermal and morphological properties of microcrystalline cellulose particles prepared from cotton slivers using different acid concentrations. Cellulose 16 (5), 783-793.

Das, K., et al., 2010. Study of the properties of microcrystalline cellulose particles from different renewable resources by XRD, FTIR, nanoindentation, TGA and SEM. J. Polym. Environ. 18 (3), 355-363.

Doyle, C.D., 1961. Kinetic analysis of thermogravimetric data. J. Appl. Polym. Sci. 5 (15), 285-292.

El-Sakhawy, M., Hassan, M.L., 2007. Physical and mechanical properties of microcrystalline cellulose prepared from agricultural residues. Carbohydr. Polym. 67 (1), 1-10.

Flynn, J.H., Wall, L.A., 1966. A quick direct method for determination of activation energy from thermogravimetric data. J. Polym. Sci. Polym. Lett. 4 (5PB), 323-328.

Friedman, H.L., 1964. Kinetics of thermal degradation of char-forming plastics from thermogravimetry. Application to phenolic plastic. J. Polym. Sci. Polym. Sym. (6pc), 183-195.

Jiang, G.Z., et al., 2010. A systematic study of the kinetics of lignin pyrolysis. Thermochim. Acta 498 (1-2), 61-66.

Kim, J.S., et al., 2001. Cellulose hydrolysis under extremely low sulfuric acid and high-temperature conditions. Appl. Biochem. Biotechnol. 91-3 $331-340$.

Kim, U.J., et al., 2010. Thermal decomposition of native cellulose: influence on crystallite size. Polym. Degradr. Stabil. 95 (5), 778-781.

Kissinger, H.E., 1957. Reaction kinetics in differential thermal analysis. Anal. Chem. 29 (11), 1702-1706.

Nelson, M.L., Conrad, C.M., 1948. Improvements in the acid-hydrolysis method of determining the crystallinity of cellulose. Text. Res. J. 18 (3) $149-164$.

Ozawa, T., 1965. A new method of analyzing thermogravimetric data. Bull. Chem Soc. Jpn. 38 (11), 1881-1886.

Poletto, M., et al., 2011. Crystalline properties and decomposition kinetics of cellulose fibers in wood pulp obtained by two pulping processes. Polym. Degradr. Stabil. 96 (4), 679-685.

Ramajo-Escalera, B., et al., 2006. Model-free kinetics applied to sugarcane bagasse combustion. Thermochim. Acta 448 (2), 111-116. 
Segal, L., et al., 1959. An empirical method for estimating the degree of crystallinity of native cellulose using the X-ray diffractometer. Text. Res. J. 29, 786-794.

Shafizadeh, F., 1985. Pyrolytic reactions and products of biomass. In: Overend, R.P., Milne, T.A., Mudge, L.K. (Eds.), Fundamentals of Thermochemical Biomass Conversion. Elsevier, London, pp. 183-214.

Sharples, A., 1957. The hydrolysis of cellulose and its relation to structure. Trans. Faraday Soc. 53 (7), 1003-1013.

Shen, D.K., Gu, S., 2009. The mechanism for thermal decomposition of cellulose and its main products. Bioresour. Technol. 100 (24), 6496-6504.

Tang, L.G., et al., 1996. Evaluation of microcrystalline cellulose. I. Changes in ultrastructural characteristics during preliminary acid hydrolysis. J. Appl. Polym. Sci. 59 (3), 483-488

TAPPI, 2002. TAPPI Test Methods, T222 om-02. Acid-insoluble Lignin in Wood and Pulp. TAPPI Press, Atlanta.

TAPPI, 1993. TAPPI Test Methods, T211 om-93, Ash in Wood, Pulp, Paper and Paperboard: Combustion at $525^{\circ} \mathrm{C}$. TAPPI Press, Atlanta.
TAPPI, 2000. TAPPI Test Methods, T249 cm-00, Carbohydrate Composition of Extractive-free Wood and Wood Pulp by Gas-liquid Chromatography. TAPPI Press, Atlanta.

TAPPI, 1997. TAPPI Test Methods, T204 cm-97, Solvent Extractives of Wood and Pulp. TAPPI Press, Atlanta.

Wang, S., et al., 2007. Mechanism study on cellulose pyrolysis using thermogravimetric analysis coupled with infrared spectroscopy. Front. Energy Power Eng. Chin. 1 (4), 413-419.

Xiang, Q., 2002. Conversion of Lignocellulosic Substrate into Chemicals: Kinetic Study of Dilute Acid Hydrolysis and Lignin Utilization, Ph.D. Thesis. University of Auburn, Alabama.

Xiang, Q., et al., 2003a. A comprehensive kinetic model for dilute-acid hydrolysis of cellulose. Appl. Biochem. Biotechnol. 105, 337-352.

Xiang, Q., et al., 2003b. Heterogeneous aspects of acid hydrolysis of alpha-cellulose. Appl. Biochem. Biotechnol. 105, 505-514. 